\title{
A DIALÉTICA DO LATIFÚNDIO E MINIFÚNDIO: A POLÍTICA AGRÁRIA BOLIVIANA NOS ÚLTIMOS 60 ANOS $^{1}$
}

\author{
THE DIALECTIC OF LANDLORDISM AND SMALLHOLDINGS: THE BOLIVIAN \\ AGRARIAN POLICY IN THE LAST 60 YEARS
}

\author{
Aldo Duran Gil ${ }^{2}$ \\ Universidade Federal de Uberlândia (UFU), Brasil.
}

\begin{abstract}
Resumo: O objetivo deste artigo é apresentar uma análise da política agrária boliviana pós-1953. Para entendermos o conteúdo dessa política estatal e sua natureza de classe, buscamos caracterizar seus os principais aspectos estruturais de longo prazo, tomando em conta o contexto de transformações socioeconômicas e políticas pós-1953, passando rapidamente pelos regimes populista, militar e neoliberal. Partimos da hipótese segundo a qual a política agrária boliviana adotou um padrão estrutural de Reforma Agrária conhecido como modelo junker, reproduzindo a longo prazo o grande latifúndio e o minifúndio.
\end{abstract}

Palavras-chave: Reforma Agrária; Desenvolvimento Capitalista Dependente; Bolívia.

\begin{abstract}
The objective of this article is to present an analysis of the post-1953 Bolivian agrarian policy. In order to understand the content of this state policy and its class nature, we seek to characterize its main long-term structural aspects, taking into account the context of post-1953 socio-economic and political transformations, passing quickly through populist, military and neoliberal regimes. We start from the hypothesis that Bolivian agrarian policy adopted a structural pattern of Agrarian Reform known as a junker model, reproducing in the long term the large landlordism and smallholdings.
\end{abstract}

Keywords: Land Reform; Dependent Capitalist Development; Bolivia.

\section{INTRODUÇÃO}

O objetivo deste artigo é apresentar uma análise da política agrária boliviana do período pós 1953. Para entendermos o conteúdo dessa política estatal e sua natureza de classe, buscamos caracterizar seus os principais aspectos estruturais de longo prazo, tomando em conta o contexto de transformações socioeconômicas e políticas pós-1953, passando rapidamente pelos regimes populista, militar e neoliberal (1953-2003). Mais especificamente, a ideia é caracterizar seus traços essenciais ao longo de mais de 50 anos. Partimos da hipótese segundo a qual a política agrária boliviana adotou um padrão estrutural de Reforma Agrária

\footnotetext{
1 Parte da primeira versão deste artigo foi disponibilizado nos Anais do V Congresso Latino-Americano de Ciência Política, da Associação Latino-Americana de Ciência Política (ALACIP), Buenos Aires, 2010. Ele fez parte da pesquisa realizada em 2007 e 2008 sobre o governo Morales e publicada nos artigos "Bolívia e Equador no contexto atual" (DURAN, 2008a), "Bolívia: duas revoluções nacionalistas?" (DURAN, 2008b) e "A política agrária boliviana sob o governo Morales” (DURAN, 2013). A presente versão do artigo aborda a primeira parte: a política agrária boliviana pós-1953.
}

Doutor, Professor Adjunto da Universidade Federal de Uberlândia (UFU). E- mail: aduran@ufu.br. 
conhecido como modelo junker, reproduzindo a longo prazo o grande latifúndio e o minifúndio.

\section{POLÍTICA AGRÁRIA BOLIVIANA PÓS-1953}

\section{A Reforma Agrária boliviana de 1953 foi implementada no contexto de} transformações socioeconômicas e políticas de cunho nacionalista, aqui caracterizada como um tipo de revolução burguesa de tipo atrasada e periférica no âmbito sul-americano. Embora tal reforma tenha se apresentado como avançada no contexto latino-americano, o modelo de reforma aplicado teve sérias contradições e limites estruturais bem definidos.

\subsection{TRAÇOS ESSENCIAIS DA REFORMA AGRÁRIA DE 1953}

No fundamental, os traços essenciais do modelo boliviano se assemelham a uma variante de transição ao capitalismo denominada por Lênin como transformação "pelo alto", de tipo junker. Seu caráter avançado residiu basicamente em três aspectos.

Primeiro, na tentativa de eliminação parcial (mas não completa) de relações semiservis vigentes até então no campo: um tipo de colonato ${ }^{3}$ conhecido no país como pongueaje: prestação de sobre trabalho compulsório do indígena-camponês (ou camponês-indígena) ${ }^{4}$ ao

3 Trata-se de um fenômeno de exploração de trabalhadores do campo que maioria dos autores no Brasil denomina colonato (com suas diversas formas de exploração do trabalho e de formas de produção nas distintas regiões da América Latina), caracterizado pela prestação de sobre trabalho compulsório e gratuito do trabalhador direto ao patrão latifundiário, na qual predominam relações de produção semi-servis e semi-assalariadas e de dependência pessoal do trabalhador diante do patrão (Cf. PRADO JR, 1977; CARDOSO, C. F. S; BRIGNOLLI, H. P., 1983; CARDOSO, C. F. S, 1987; SAES, 1985; MARTINS, J. S., 2010; entre outros).

4 Utilizaremos indistintamente o termo composto indígena-camponês e camponês-indígena para designar, indicativamente, o camponês. Este tem um caráter étnico e de classe (camponês), ou seja, sua dupla identidade: indígena e camponês, ou indígena que vira camponês ou camponês de origem indígena. Já a identidade propriamente étnica se articula à comunidade indígena (ayllus), cujos grupos e membros tem, na década de 1950, pouco contato com as regiões semi-urbanas e urbanas; embora tal contato tenha mudado e oscilado ao longo dos últimos 60 anos através dos mercados camponeses em regiões semi-urbanas e urbanas, dos programas de colonização promovido pelo Estado no âmbito da reforma agrária, bem como através dos fluxos migratórios internos (de indivíduos ou famílias camponesas que se deslocam às cidades em busca emprego e de melhores condições de vida) nas regiões das grandes cidades andinas e sub-andinas. As problemáticas indígena e camponesa são complexas na Bolívia, um país de maioria indígena. Sabe-se que as forças dirigentes pequenoburguesas (partido Movimiento Nacionalista Revolucionario, MNR) na Revolução Nacional de 1952 buscou a campesinização dos indígenas (predominando as etnias quechua e aymara na concepção do Estado, excluindo as etnias das terras baixas); ou então, declarar os indígenas trabalhadores (pongos domésticos e de fazendas) em camponeses. A questão indígena é deturpada aparecendo como problemática camponesa. O que significa que os indígenas foram, no vocabulário sociopolítico dessa revolução, não só excluídos, mas também ignorados, sendo imposto pelo Estado formado em 1952 uma identidade compatível com o nacionalismo revolucionário, de caráter colonialista e racista conforme a análise dos autores sobretudo indigenistas bolivianos (principalmente os kataristas), como Reinaga (1970), Rivera (1983, 1984, 2012) e Rivera \& Santos (2014). Algo diferente ocorrerá 
patrão latifundiário; porém tais relações permanecem no campo com intensidade variável, dependendo da região, até pelo menos a década de 2010, como veremos mais à frente.

Segundo, na distribuição de terras fiscais ao indígena-camponês pobre na forma de minifúndios ou pequenas parcelas compostas de três a dez hectares.

Terceiro, na tentativa de implementação de uma política de substituição de importações de tipo agrícola (substituição de alimentos). O que acabou encorajando a emergência de uma burguesia agrária (voltada para a produção de grãos: trigo, cana de açúcar, algodão, soja etc.; e agropecuária: principalmente produção de gado) e da economia indígena camponesa de subsistência num contexto de crescente pauperização do campo boliviano.

Esses aspectos integravam a política agrária do novo regime surgido da Revolução Nacional de 1952. Este regime nacionalista, comandado pelo partido MNR, aplicou seu programa político de cunho desenvolvimentista burguês em detrimento do programa da classe operária mineira estampado nas Tesis de Pulacayo, classe essa que perdeu a direção do processo político para a pequena burguesia nacionalista (LORA, 1987). No plano ideológico, tal política contemplava, senão a destruição pelo menos o controle do grande latifúndio por parte do Estado em favor do campesinato-indígena pobre. A expansão do minifúndio aparece assim como um aspecto importante da política agrária do novo regime, sendo acompanhada de um programa de colonização e assentamento de grandes contingentes de camponesesindígenas em regiões inóspitas, longe da fronteira agrícola. O que provocou a adesão massiva do campesinato-indígena pobre das terras altas e populosas das regiões andina e sub-andina à política agrária governamental, constituindo-se como um grande segmento da base social de apoio ao regime.

\subsection{PRINCIPAIS CONTRADIÇÕES E LIMITES DA POLÍTICA AGRÁRIA DE 1953}

Agora vejamos as principais contradições e limitações dessa política agrária. Para tanto, foquemos o conteúdo de tal política e, sobretudo, seu caráter sócio-estrutural. ${ }^{5}$

A política agrária imposta ao campesinato-indígena de parcelar instaurou um sistema de dominação dessa classe que se concretizou num tipo de patronato político: o "Estado

na "revolução indigenista e agrária" (na acepção de seus dirigentes) levada a cabo pelas forças,MAS-governo Morales a partir de 2006. (Cf. DURAN, 2013).

5 Por sócio estrutural nos referimos ao caráter histórico da formação social boliviana de longo prazo, com o primado da estrutura sobre a conjuntura (diferentemente das análises conjunturais), basicamente utilizamos essa terminologia na acepção da articulação recíproca (ação e reação) entre economia e política proposta por Marx-Engels (um aspecto que diz respeito à teoria marxista da história) e que vigora na reprodução ampliada do capital. Mais especificamente, nos baseamos na análise da articulação dos processos econômico e político constante nos trabalhos de Poulantzas (1968) e Saes (1985a, 1985b, 1994, 2001a, 2001b, entre outros). 
patrão". A amálgama de relações de produção pré-capitalista com a outorga de certas concessões sociais e políticas de tipo capitalistas (abolição formal do colonato; direito a uma pequena parcela; direito de organização sindical camponesa-indígena e sufrágio universal) apareceu sob a forma de tutela do Estado sobre os camponeses-indígenas parcelares, cujo elemento predominante foi o clientelismo, amplamente capitalizado pelos governos do MNR (1952-64) e pelos governos militares (1964-1982).

No penúltimo governo de Paz Estenssoro se criou o Pacto Militar Camponês Anticomunista (abril de 1964) sob o comando do general Barrientos. O governo Siles (195660) havia delegado a este militar a tarefa de pacificar as lutas intestinas entre os setores do campesinato-indígena, incentivadas pela acirrada luta de facções do MNR pela conquista do poder governamental via eleições. Albó e Barnadas (1985) sustentam que no final dos anos 1950 se criaram "super-Estados" camponeses (amplas regiões controladas por caciques e caudilhos camponeses-indígenas armados) que surgiram para defender tanto a reforma agrária de 1953 como o governo. Tais "super-Estados", teriam entrado em guerra uns contra outros incentivados pelo governo. Mas, no fundamental, os camponeses-indígenas teriam sido tutelados politicamente pelo Estado (MNR, militares), o que é designado pelo termo pongeaje polítical (servidão política), semelhante ao coronelismo ${ }^{7}$ no Brasil.

Já entre 1964 e 1978 predominou a tutela militar: um tipo de patronato militar materializado no Pacto-Militar Camponês. Embora alguns setores do campesinato-indígena lutem pela sua autonomia nesse período, esta será conquistada pelo conjunto do campesinato de origem indígena somente entre 1979 e 1980: a aliança entre organizações sindicais do campo e da cidade na luta contra o regime militar concretizada pelo reingresso da Confederación Sindical Única de Trabajadores Campesinos de Bolívia (CsuTCB) à Central Obrera Boliviana (COB).

\footnotetext{
6 Esse "Estado patrão" também é evocado por Rivera (1983). Contudo, esses autores não conseguem perceber que trata-se de um processo de desorganização/reorganização característica do Estado burguês em relação às classes dominadas, principalmente do campesinato que, neste contexto, cumpre o papel de classe apoio do bloco no poder; e que está articulado a um processo lento de conservação/dissolução das relações de produção pré-capitalistas no campo: a preservação da grande propriedade fundiária (e a impossibilidade de transformar esta classe em fração burguesa) e a implementação de uma política desenvolvimentista-populista pautada pela preservação da ordem social capitalista periférica.

Mais especificamente, tal pongeaje política na Bolívia no período pós-1953, sob os governos do MNR (1952-1964), se aproxima daquilo que Saes denomina - na redefinição desse conceito - "coronelismo" (SAES, 1998, pp. 71-113).
} 
Assim, partimos da hipótese segundo a qual as relações de produção pré-capitalistas no campo viabilizaram práticas políticas que foram potencializadas pelo clientelismo $^{8}$, amplamente detectado por vários autores como Alexander, Mitchel, Malloy, Zavaleta e Lavaud, entre outros. Mas foi interpretado como um fenômeno anormal e "perverso" - isto é, um fenômeno corruptor - ao longo do processo político boliviano dos anos 1950 a 1970, sem diferenciar os dois tipos de relações e suas mudanças - isto é, relações de produção précapitalista e relações de produção capitalistas, com relativo predomínio destas últimas. $\mathrm{Ou}$ então, foi entendido como constitutivo $d a$ sociedade boliviana, entendida como caótica e instável por natureza, com alto índice de politização, como sustenta Lavaud (1991), apoiado nas teses defendidas por Huntington (1975) em relação às sociedades pretorianas de massa.

As relações de produção capitalistas caminham lentamente em nichos tipicamente inseridos em relações de trabalho assalariado e semi-assalariado: setor extrativo de minérios (estatal e privado), indústria manufatureira, e setor anexo à economia mineiro-extrativa (comércio importador-exportador e serviços: bancos, comércio, funcionalismo público). Num contexto em que a população boliviana mora majoritariamente no campo e sobrevive da economia de subsistência e com nível muito baixo de assalariamento. Com efeito, no final dos anos 1970 cerca da terceira parte da população boliviana vivia no campo (58\% em 1976), com um ritmo de diminuição muito lento em 30 anos (72\% em 1950 e 55,5\% em 1980). Um relatório da CEPAL de 1982 registrou 380 mil famílias que dependiam da agricultura camponesa de subsistência nos anos 1970; e outro documento do INE (Instituto Nacional de Estadística) registra 697 mil pessoas integrantes da PEA agrícola de 1976 (46,4\% da PEA total), cuja maioria (86,3\%) não era assalariada. Os dados da CEPAL (1982) sugerem que a PEA agrícola seria maior do que a registrada pelos dados oficiais: entre 55\% e 60\%. Albó (1976) sugere 1,5 milhão de pessoas que dependem da agricultura de subsistência.

Esse seria o outro caráter da economia boliviana qualificada por nós como agráriocamponesa/indígena (aqui incluído os nichos de agricultura ligeiramente modernizada na região leste do país). Nesse sentido, a economia do país pode ser enquadrada numa de tipo enclave mineiro-extrativa. ${ }^{9}$ Daí seu duplo caráter da formação social boliviana ainda vigente nas décadas de 1970 e 1980: agrário-camponesa/indígena e mineiro-extrativa. ${ }^{10}$

\footnotetext{
8 Dissemos potencializadas pelo clientelismo porque este fenômeno político, que não é pré-moderno ou pré-capitalista, mas regular nas democracias capitalistas centrais, inclusive nas democracias mais desenvolvidas, conforme mostram vários autores como, por exemplo, Theobald (1992).

9 Alguns autores abordam a questão do extrativismo e neoextrativismo, passando a considerar a Bolívia, pelo menos desde os anos 1950, como um país de economia extrativista. Sobre essa questão, ver: Petras e Lora (2013), Zibechi (2014, 2016), Gudynas (2015), entre outros. Para Gudynas, todo extrativismo, independentemente de sua variação, é predatório devido a seus efeitos "derrame" (consequiências) negativos,
} 
A abolição formal no decreto da reforma agrária em 1953 (um ensaio foi feito dez anos antes) das relações de produção servis no campo boliviano não eliminou completamente tais relações de produção, sendo ainda conservadas - embora se detecte um lento processo de dissolução - nos anos 1970-1980 em algumas regiões onde predomina a grande e média propriedade fundiária e no campo em geral. Vários autores que analisaram o processo de transformação capitalista desencadeada pela reforma agrária boliviana detectaram relações de produção servis nas regiões sul (departamento de Chuquisaca) e sudeste (departamento de Santa Cruz, basicamente na província Cordillera) em plenas décadas de 1970 e $1980 .{ }^{11}$

A presencia do campesinato de origem indígena e população propriamente indígena na Bolívia é predominante, com níveis de pobreza acentuada que sobrevive tanto da economia camponesa de subsistência em pequenas parcelas de terra (minifúndios) como do trabalho assalariado nos nichos de economia capitalista mais avançada no campo e nas parcelas do campesinato rico, com níveis elevados de exploração, principalmente do campesinatoindígena pobre e sem-terra. Inclusive, encontram-se casos em que migrantes colonos de terras altas (de origem indígena) que se assentaram em terras baixas com ou sem ajuda do Estado (programa de colonização induzida com o objetivo de fornecer mão de obra barata para os nichos de economia agrária capitalista) passaram não só a explorar mão de obra de etnias indígenas de terras baixas em condições de semi-assalariamento, mas também em condições de escravidão. A análise de Healy (1987) detecta em plena década de 1980 esses casos em regiões leste e centro-sul do país onde predomina população indígena das etnias guarani e chiriguano. Os médios e grandes fazendeiros das regiões Cordillera e Chaco (departamentos de Santa Cruz e Chuquisaca) do país também escravizaram sessa etnias indígenas durante

que contaminam ou vão além dos danos locais de uma determinada atividade extrativa, tendo impacto sobre o uso dos territórios, as dinâmicas econômicas, a inserção internacional, o papel do Estado, bem como as formas de fazer política (democracia). Assim, o Estado extrativista passa a defender esse tipo de atividade como "bom negócio" e como a única forma de inserção com vantagens mais ou menos competitivas no mercado globalizado. Apesar de ser um trabalho importante, nos distanciamos do autor no que diz respeito ao caráter obscuro e idealista em relação a superação da economia extrativa e neoextrativa, se aproximando de posturas ecologistas um tanto românticas no modo de produção capitalista.

10 Sobre o duplo caráter da formação social boliviana ao longo do século XX, ver Duran Gil (2003), principalmente capítulo II ("Formação social capitalista periférica boliviana nos anos 70").

11 Um significativo estudo sobre as relações sociais no campo boliviano, feito nas províncias sulinas do Departamento de Chuquisaca entre 1974 e 1976, foi realizado por Healy (1987). Sobre o departamento de Santa Cruz, ver Castillo \& Ballerstaedt (1983), Bojanic (1988), Arrieta; Ábrego; De la Fuente (1990) e Ybarnegaray (1992). No caso desta região, tanto os "junkers" e as frações agrárias e agroindustriais, como os representantes políticos destas classes (certas camadas médias), controlam os aparelhos estatais locais e regionais, não se diferenciando das práticas políticas das pequenas "elites agrárias" descritas por Healy: também açambarcaram os volumosos orçamentos públicos destinados para esta região, bem como os enormes recursos oriundos dos royalties petrolíferos (18\% e 11\%) durante a década de 1970. O famoso Comité Pró Santa Cruz não passou de um partido político regional que representou os interesses econômicos e políticos da grande média propriedade fundiária, bem como do capital petrolífero presente na região. 
décadas. Esses casos de escravidão foram redescobertos e denunciados pelos próprios indígenas guarani da APG (Assembleia de Povos Guarani - APG) à OIT nos anos 2000, durante o período do primeiro governo Morales. Uma reportagem de uma jornalista brasileira ajudou a difundir essa situação em nível no âmbito internacional no livro "Em luta pela terra sem mal" (PIVA, 2012).

Nas regiões tradicionais com alta densidade de população camponesa-indígena (regiões andina e andina sub-andina), onde a distribuição de minifúndios foi mais acentuada, a maioria dos camponeses-indígenas pobres (ex-colonos dependentes do patrão) liberta-se do trabalho compulsório (colonato) por obra da pressão do movimento operário mineiro em 1952 em conjunto com os movimentos camponeses-indígenas aliados, e passa a se converter em "proprietário" de uma pequena parcela de terra, em pequeno produtor agrícola e em trabalhador assalariado. O que não significa que tal libertação seja automática e completa, pois o grau de assalariamento no campo continuou sendo muito baixo ou nulo e conviveu simultaneamente com relações de produção servis e semi-servis.

Vejamos mais de perto. A terra ocupada pela maioria dos camponeses-indígenas parcelares ainda pertencia juridicamente ao Estado. Trata-se de um dos aspectos essenciais da reforma agrária boliviana de 1953: a concessão feita pelo Estado a essa fração de classe dominada através da legislação agrária se configurou, simultaneamente, como tutela do Estado sobre o camponês parcelar e como agrilhoamento deste ao minifúndio.

\subsection{A REFORMA AGRÁRIA NA CONSTITUIÇÃO DE 1967}

Nossa análise detectou esse fenômeno que aparece no duplo dispositivo jurídico referente ao assunto na Constituição de 1967.

Primeiramente, o camponês-indígena parcelar não podia vender sua terra, conforme declara o artigo 167 (que reproduz os artigos 6 e 7 da Lei da Reforma Agrária de 1953 referente ao caráter da propriedade e posse da parcela pelo camponês): a parcela é declarada "intransferível" e "inalienável". Porém o mesmo artigo demonstra o outro aspecto da reforma: embora mencione o não reconhecimento do latifúndio pelo Estado, este ao mesmo tempo o protege, o que aparece nos seguintes termos: "a média propriedade e a empresa agropecuária reconhecidas por lei gozam da proteção do Estado, desde que cumpram uma função econômica e social”. Este dispositivo jurídico (função econômica e social) mascara a proteção do grande latifúndio por parte do Estado. 
Em segundo lugar, o dono da terra é o Estado, que tem a prerrogativa de distribuir e redistribuir a propriedade agrária conforme as necessidades econômicas e sociais e de desenvolvimento rural (art. 165) - isto é conforme os interesses da grande propriedade fundiária e das frações burguesas agroindustriais. Esses dispositivos jurídicos são reforçados por outro, no qual aparece claramente que a outorga dos títulos de propriedade estava condicionada pelo trabalho da terra: praticamente exigia a permanência do camponês na parcela concedida temporariamente pelo Estado, caso contrário perderia sua parcela.

Em terceiro lugar, para complementar esse quadro, a tramitação dos títulos das minis parcelas era bloqueada sistematicamente por inúmeras travas burocráticas: na maioria dos casos demorava mais de vinte anos - essa era a situação em que se encontravam a maioria dos camponeses-indígenas no final dos anos 1970 e inícios dos 1980. Tratava-se de uma concessão parcial do Estado viabilizado politicamente pelo programa de reforma agrária, o que foi bem aproveitado pelas políticas agrárias do Estado populista e do Estado militar para agrilhoar o camponês-indígena à terra e assegurar lealdade política tanto aos dirigentes do MNR quanto aos militares, integrantes da burguesia de Estado nascida ao longo do processo socioeconômico e político pós-1952 (Revolução Nacional de 1952).

Agora temos condições para completar a análise do conteúdo da política agrária do Estado formado em 1952. A Reforma Agrária de 1953, não conseguiu realizar uma substantiva transformação capitalista no campo boliviano. Consolidou e expandiu, simultaneamente, a grande propriedade fundiária, em cuja base criou um nicho de agricultura capitalista na região leste do país, e distribuiu pequenas parcelas ao campesinato-indígena pobre.

Mas especificamente, tal reforma instaurou um regime agrário com um duplo sistema de propriedade e de exploração da terra. De um lado, um sistema de minifúndio que reproduz a agricultura camponesa de subsistência, caracterizada pelo trabalho familiar, pela baixa produtividade, bem como pela utilização de técnicas rudimentares de exploração da terra. Numa palavra, tal sistema contribuiu para aprofundar o processo de pauperização e proletarização do campesinato-indígena em geral.

De outro, instaurou um sistema baseado na alta concentração da propriedade fundiária configurada no médio e grande latifúndio (principalmente na região leste, onde se encontram as melhores terras: sobretudo o departamento de Santa Cruz, seguido dos departamentos Beni e Pando), cuja forma de exploração da terra é designada como agricultura "moderna". E esta caracteriza-se tanto pela utilização simultânea de trabalho assalariado e semi-assalariado (trabalho pago em dinheiro e em espécie), porém com baixa capacidade de absorção de mão 
de obra e alto índice de exploração da força de trabalho de origem camponesa-indígena. A maioria dos trabalhadores do campo (estacionários ou não) são oriundos das regiões andina e sub-andina. Trata-se, assim, de um nicho de agricultura capitalista voltado para a produção comercial e para a exportação de produtos agroindustriais (algodão, açúcar, soja) e que convive com o grande latifúndio improdutivo. Nos anos 1960 e 1970, a política agrária se orientou essencialmente ao reforço da expansão deste tipo de agricultura.

Em suma, tanto o sistema de propriedade parcelar camponesa (produção camponesa de subsistência) como o sistema de propriedade do grande e médio latifúndio foram institucionalizados pela Reforma Agrária em 1953. Nos dois sistemas, as relações de produção capitalistas são muito fracas e avançam num ritmo muito lento. No primeiro sistema predomina a produção camponesa-indígena de subsistência, mas o camponês é obrigado a complementar sua renda com trabalho assalariado e semi-assalariado. $O$ processo pauperização dos camponeses parcelares (principalmente de camponeses sem terra) é muito acentuado: a maioria migra para as cidades e para as regiões onde vigoram os nichos de agricultura capitalista. Já no segundo sistema vigoram relações de produção pré-capitalistas (trabalho de tipo servil) que convivem com fracas relações de produção capitalista (trabalho assalariado e semi-assalariado). Nesta região, os camponeses-indígenas são altamente explorados e obrigados a se assentar em novas colônias (adquirindo pequenas parcelas e adotam a agricultura de subsistência) sem ajuda do Estado, voltar a suas regiões de origem, ou fugir para os países vizinhos (Argentina, Brasil) em busca de trabalho e de melhores condições de vida.

\subsection{ESTRUTURA FUNDIÁRIA E FRAÇÕES DE CLASSE DOMINANTES}

Não se pode entender o conteúdo da política agrária boliviana pós-1953 sem relacionála com a estrutura fundiária e o sistema de dominação de classes que vigorou ao longo dos anos 1960 a 1980. Para tanto, impõe-se uma breve caracterização da grande e média propriedade fundiária e as frações burguesas articuladas a essas classes sociais. Ao contrário do que mormente se sustenta, a grande propriedade fundiária, aliada política da velha burguesia mineira, saiu fortalecida no pós-1952. A Reforma Agrária não apenas consolidou, mas também contribuiu com a maior concentração e expansão da grande propriedade fundiária - impulsionou uma transformação no campo de tipo junker na região leste do país. 
No processo de diferenciação ${ }^{12}$, no seio destas classes, consoante ao tipo de desenvolvimento capitalista instaurado na Bolívia, pode-se detectar o surgimento de duas frações burguesas importantes: a agrário-comercial e a agroindustrial. ${ }^{13}$ Deste conjunto de classe emerge o capital agroexportador que foi amplamente incentivado pelo Estado, principalmente na exportação de algodão, açúcar e álcool. Em geral, tais classes atravessam um período de fortalecimento político e relativo crescimento econômico, o que se expressou no atendimento de seus interesses econômicos pelo Estado militar através das políticas agrária e agrícola. A política agrária instaurou, a partir de 1969, uma segunda fase de expansão e concentração da grande propriedade fundiária (a primeira fase de consolidação e expansão: 1953-69). Já a política agrícola viabilizou a transferência de capital ao setor via créditos estatais com fundos perdidos, isenção de impostos e subvenção dos preços dos principais produtos agroindustriais (algodão, açúcar, álcool etc.) e agropecuários (principalmente gado).

Por outro lado, devemos salientar dois aspectos importantes do caráter destas classes e frações proprietárias. Os setores econômicos preponderantes pertencem à região de Santa Cruz (onde se concentra a maior parte da grande propriedade fundiária no país), dentre os quais se destaca o setor agroexportador, porém, em geral, estes setores são representados politicamente pela burguesia agroindustriais através de seus principais órgãos corporativos de representação de interesses: principalmente a CAO (Câmara Agropecuária do Oriente), CAINCO (Câmara de Indústria e Comércio) e FEgASACRuZ (Federação de Agropecuaristas de Santa Cruz). No seu conjunto, essas classes e frações de classe dominantes regionais se apresentam, de um lado, como aliados políticos do capital estrangeiro (bancário-financeiro e petrolífero) que participa na economia regional, e de outro, como inimigos políticos potenciais do centralismo burocrático da capital do país. Vale dizer, no seu discurso regionalista constante aparecem descarregando sua luta contra a "burguesia paceña" (La Paz) em clara alusão, sobretudo, à burguesia de Estado (formada e consolidada no Estado de 1952) e, em parte, à nova burguesia mineiro-exportadora ${ }^{14}$ (que emergiu no pós-1952). Em suma, a

12 Sobre o processo de diferenciação de classe no modo de produção capitalista, consultar a célebre obra El desarrollo del capitalismo en Rusia (1981). Uma teoria atualizada e crítica sobre o fracionamento das classes dominantes no capitalismo oferece Saes em "As frações da classe dominante no capitalismo: uma reflexão teórica" (2014a). Essa reflexão visa aprofundar as hipóteses lançadas sobre o assunto no livro República do Capital (2001a) e em outros artigos, sobretudo no artigo intitulado "Capitalismo e processo político no Brasil: a via brasileira para o desenvolvimento do capitalismo" (2014b). Agradecemos ao professor Décio Saes por fornecer esses últimos artigos (como outros) mimeografados e pela autorização de citação dos mesmos.

$13 \quad$ As frações preponderantes destas classes possuem as melhores terras na região tropical e subtropical do Leste do país: Pando, Beni, Santa Cruz, Chuquisaca e Tarija - região que no período do agudo conflito (20072008) entre a grande propriedade fundiária e o governo Morales foi denominada "meia-lua".

14 Essa nova fração da burguesia mineira é diferente da velha burguesia mineira, mais conhecida como "os barões do estanho". A nova burguesia mineira surge basicamente com o Estado formado em 1952 e tende a 
luta econômica e política entre esses dois conjuntos de classe dominante apareceu, ao longo do período 1960-80, na forma de luta regional, luta esta que está relacionada com os conflitos e contradições no seio do bloco no poder.

$\mathrm{Na}$ literatura sociológica e política boliviana, esse fenômeno político foi analisado basicamente a partir de dois ângulos. De um lado, as causas fundamentais da instabilidade política boliviana estariam nas lutas regionais, dinamizadas pelas oligarquias regionais, e não na luta de classes. O maior representante é Roca (1999, p. 39), quem sustenta a tese segundo a qual a história do país não é a história da luta de classes, mas a história de suas lutas regionais (CALDERON; LASERNA, 1983). De outro, o conjunto da classe proprietária fundiária aparece com uma dupla caracterização, feita por Zavaleta, Lavaud, entre outros: 1) a não diferenciação das classes e frações de classe da região de Santa Cruz, considerando-as de forma homogênea com o qualificativo de "oligarquia cruceña"; 2) esta teria detido a hegemonia política no período 1970-1980 (IBARNEGARAY, 1992; ARRIETA; ÁBREGO; DE LA FUENTE, 1990). ${ }^{15}$

Vejamos outro aspecto importante da política agrária pós-1953. Essa política, que fazia parte da política estatal de cunho desenvolvimentista, contribuiu com a criação das condições necessárias para a emergência de uma burguesia agroindustrial. Trata-se de um processo de criação de uma nova fração burguesa "pelo alto", homólogo ao processo de emergência da nova burguesia mineira em detrimento da antiga burguesia mineira (barões do estanho). Estas duas importantes frações da burguesia boliviana - que aqui denominamos burguesia interna seguindo a análise de Poulantzas (1975), ${ }^{16}$, preponderaram na economia no período 1950-1980 - foram "criadas" pelo Estado boliviano e simultaneamente impulsionadas por este e pela política imperialista dos Estados Unidos. Mas especificamente, é o Estado boliviano que intervém na formação e consolidação destes dois núcleos de burguesia interior interna.

se consolidar na década de 1970 com apoio do Estado, que transfere boa parte da renda estanífera e petrolífera ao setor através de empréstimos com fundo perdido, isenção de impostos e compra de concentrados de minérios por parte da estatal COMIBOL (Corporacióm Minera de Bolivia) com preços sobre-faturados, entre outros. Inicialmente, as sub-frações da nova burguesia mineira se autodenominam "mineração média", aglutinadas na ANMM (Asociación Nacional de Mineros Medianos), porém são aliadas e dependentes das firmas monopolistas mineiras estadunidenses. Contudo, as firmas monopolistas estrangeiras, sobretudo estadunidenses, dirigem e controlam a ANMM, e se autodenominam, eufemisticamente, mineração média, ocultando seu caráter monopolista e oligopolista. Elas dominam o Estado boliviano e controlam a exportação de concentrados de minérios não refinados, o refino no exterior e a comercialização dos mesmos nos mercados mundiais. Sobre esse assunto, Cf. Duran (2003; ver principalmente o item "Caracterização das classes dominantes na Bolívia”, pp. 131-138).

15 Essas caracterizações são altamente discutíveis, especialmente a última. Não temos espaço aqui para aprofundar essa análise.

Nessa obra Poulantzas diferencia a burguesia compradora, burguesia interna e burguesia nacional. Nessa linha de análise sobre a burguesia interna nos apoiamos sobretudo em Saes (2014a, 2014b). 
Zavaleta (1992, p. 75-76) também detecta a criação dessas frações burguesas, só que as limita ao processo posterior a 1952 e a insere no quadro do Estado liberal-burguês que, segundo o autor, somente teria emergido na revolução de 1952. Trata-se daquilo que nós denominamos, aqui, a criação dos dois núcleos da burguesia interior interna "pelo alto", mas esse processo já estava ocorrendo na década de 1940 e que se acentua a partir de 1952. E tal política obedeceu aos imperativos do Relatório Bohan (1942), elaborado pelo funcionário estatal estadunidense Mervin Bohan (Chefe da Missão Econômica dos Estados Unidos na Bolívia), o qual acabou virando o programa político do MNR. O Relatório foi reproduzido no plano econômico elaborado por W. Guevara em 1954 (Plano Imediato de Política Econômica do Governo da Revolução Nacional de 1955, que depois foi denominado Plano de Diversificação da Produção). Tal plano solicita abertamente a ajuda econômica dos Estados Unidos, endossando os imperativos políticos e econômicos do imperialismo estadunidense na Bolívia no que diz respeito ao programa de substituição de importações de produtos agroindustriais e da "marcha ao leste" do país.

Referimo-nos aqui a emergência das frações burguesas agrária e agroindustrial do leste do país (região de Santa Cruz). Trata-se de um fenômeno de transformação "pelo alto" da "situação de classe" e de interesses econômicos de frações da grande propriedade fundiária em burguesias agrária e agroindustrial. Estas foram impulsionadas com a criação do Banco Agrícola em 1942 (processo semelhante à criação do Banco Mineiro em 1937 para beneficiar às emergentes frações da nova burguesia mineira, contra os barões do estanho) e, sobretudo, com a aplicação do Relatório Bohan pelos governos populistas (1952-64). Um dos objetivos centrais desse relatório era o de que o Estado devia criar as condições econômicas necessárias com o fim incentivar a substituição de importações de produtos agropecuários e agroindustriais. O que implicava fomentar - esse era o suposto implícito no relatório - a criação de burguesias agrárias e agroindustriais que deveriam se encarregar dessa tarefa, com o fim de eliminar a dependência do país em relação a importação de grãos e alimentos. Depois de 1952, a política desenvolvimentista do novo Estado, consoante com seu projeto de diversificação econômica, passa a promover a "criação" de uma burguesia industrial. Daí a plausibilidade da hipótese segundo a qual o programa industrial do regime do MNR (195264) foi o Relatório Bohan: o programa econômico do governo nacionalista-populista aplicado na sua integridade (constante no Plano Imediato de Política Econômica de 1954, que visava a 
diversificação econômica e a "marcha ao leste"). ${ }^{17}$ E o principal instrumento da política de Estado que viabilizou tal programa foi a Reforma Agrária de 1953, cujos principais aspectos já os conhecemos: a consolidação e expansão da grande e média propriedade fundiária. Tal política foi reforçada, simultaneamente, com os sucessivos planos governamentais de desenvolvimento e relatórios dos Estados Unidos, conforme mencionado acima: o Plano de Estabilização Econômica de 1956, elaborado pelo banqueiro estadunidense Eder, conhecido como Plano Eder. O que implicou na manutenção e consolidação dos setores chaves da economia boliviana: o extrativo (minérios, petróleo) e o agroindustrial.

Uma avaliação crítica da implementação do Relatório Bohan (políticas mineira e agrária) pelo Estado revela - ao contrário do que sustenta a maioria dos autores bolivianos que não houve "claudicação" dos governos nacionalistas do MNR diante do imperialismo estadunidense, nem muito menos contradição em relação à aplicação desse relatório, que depois virou o programa do governo do MNR e concretizado nos planos de desenvolvimento e diversificação econômica. Esses governos aplicam um plano de desenvolvimento que não é deles, mostrando assim a compatibilidade do regime do MNR (a despeito de sua postura nacionalista) com as políticas imperialistas: o objetivo fundamental era "criar" e fortalecer essas duas frações da burguesia interna ${ }^{18}$ boliviana, em detrimento, evidentemente, da expansão e diversificação industrial do próprio setor mineiro e do setor manufatureiro tradicional. Contudo, quando as frações da burguesia interior experimentam um crescimento econômico e fortalecimento político nos anos 1960, passam a se opor à "política desenvolvimentista" viabilizada pelo Estado formado em 1952. Além disso, desconhecem seu “criador" (o Estado nacionalista/populista) e aplicam os golpes de 1964 e 1971 com o apoio dos militares conservadores.

Com a redefinição da ideologia nacionalista viabilizada pelas novas "categorias sociais" de Estado (militares, burocracia estatal, intelectuais, nacionalistas), os governos militares instaurados em 1964 e, sobretudo, em 1971, levaram ao limite o projeto de desnacionalização da economia boliviana iniciado no Estado populista em proveito de um

17 Essa hipótese é sugerida no trabalho de Arrieta Ábrego; De la Fuente (1990: pp. 90, 179.) sobre o caráter da agricultura e da empresa modernizada em Santa Cruz. Os autores fazem uma minuciosa análise dos planos de desenvolvimento para a agricultura à luz do Relatório Bohan e dos logros da política governamental do MNR constantes em "Bolivia: 10 años de Revolución” de 1962. O outro aspecto fundamental do Relatório era incentivar o governo boliviano na criação de condições de substituição de importações de alimentos e, por essa via - e este é o outro fator crucial, que não aparece na leitura desses autores - o de garantir, a médio e longo prazos, a extração de recursos energéticos (gás e petróleo) pelas firmas monopolistas estadunidenses. A "marcha ao leste" (região de inesgotável reserva desses produtos) deve ser entendida nesse contexto. A imposição do Novo Código do Petróleo (1955) aponta nessa direção.

$18 \quad$ Na acepção de Poulantzas (1975) e Saes (2014a e 2014b). 
“capitalismo privado". O que implicou na implementação contínua de uma política de Estado calcada no reforço dessas duas principais frações da burguesia interior. A influência dos Estados Unidos, desde a década de 1940, foi decisiva na aplicação dessa política de Estado na Bolívia: o seu objetivo era possibilitar a penetração do capital estadunidense no país, nomeadamente nos setores mineiro e petrolífero. As duas frações da burguesia interior mais importantes constituíram-se, assim, em "pontas de lança" (isto é, suas melhores aliadas) da penetração e expansão desse capital através do complexo processo de interiorização no seio da formação social capitalista periférica boliviana. O que redundou no reforço da economia de enclave ao longo do século XX, caracterizada como mineiro-extrativa e agráriocamponesa/indígena e mineiro-extrativa.

A economia camponesa-indígena de subsistência, articulada ao sistema de mini parcelas, veio então a contribuir, direta ou indiretamente, no processo de expansão da economia "agrícola modernizada" e de consolidação da concentração do grande e meio latifúndio no país - dois aspectos decorrentes da política agrária impulsionada pela reforma agrária de 1953. Além disso, a reforma tentava fornecer grandes contingentes de força de trabalho barata à região onde se instaurou um nicho de produção agrícola modernizada no âmbito de um projeto mais amplo de capitalização do campo, financiado basicamente pela renda estanífera e petrolífera (sobretudo da primeira).

\subsection{BREVE RESUMO DOS PERÍODOS DE ACUMULAÇÃO E CONCENTRAÇÃO DE TERRA $^{19}$}

Para completarmos o quadro da implementação da política agrária com seu duplo caráter, já apresentado, uma das principais políticas do Estado boliviano a médio e longo prazos, devemos salientar que o processo de acumulação e concentração de terras em poucas mãos foi feito, grosso modo, por duas vias: 1) pela via da dotação de terras fiscais pelos governos civis (MNR do período 1953-1964; período neoliberal, 1985-2005) e governos militares (1964-1982) a integrantes da burocracia estatal (dirigentes nacionalistas, cúpula castrense) e a integrantes de famílias latifundiárias e burguesas; 2) pela via da grilagem de terras por parte desses setores sociais e de setores médios aliados dos governos de turno. Nos dois casos, os mecanismos de apropriação de terras ocorrem principalmente, mas não

19 O nosso objetivo aqui é tão somente apresentar um breve resumo do açambarcamento e acumulação de terra durante os seguintes períodos: do regime ditatorial-militar (1964-1982), do governo Siles Suazo (19821985), da instauração do neoliberalismo (1985-2000). Uma análise mais aprofundada desses períodos será feita em outro momento. 
exclusivamente, na região leste do país. Lembremos que a própria legislação sobre a Reforma Agrária de 1953, ratificada pela Constituição de 1967, legitimava juridicamente esses mecanismos de açambarcamento de terras (fiscais ou não), principalmente das terras comunais indígenas, cuja forma de expropriação era feita por meio de um processo violento de extorsão ou roubo das terras dos camponeses e indígenas. E tais mecanismos de expropriação eram legitimados através do dispositivo "função econômica e social" da média e grande empresa agrícola: um processo de maqueamento do grande e médio latifúndio.

Podemos detectar três períodos do processo de consolidação-expansão do grande e médio latifúndio à luz das duas vias de açambarcamento ou expropriação de terras supramencionadas: 1) período 1964-1982 (governos do MNR): consolidação do antigo latifúndio na Reforma de 1953 com ligeira expansão da dotação de novas terras por obra da política agrária e a política desenvolvimentista do regime populista boliviano; 2) período 1964-1982 (regime militar): expansão acelerada e consolidação de novos latifúndios ${ }^{20}$;) período 1985-2005 (governos neoliberais): aprofundamento da expansão acelerada e grande concentração de terras articulada à luta pela nova consolidação do grande latifúndio. ${ }^{21}$

Analisemos brevemente o último período no qual a pauperização no campo (campesinato-indígena) chega a níveis dramáticos e coincide com o aumento igualmente dramático de empobrecimento das grandes massas populares urbanas por obra da política estatal neoliberal. A luta de classes no campo e na cidade adota um caráter altamente explosivo neste período. Do lado dos antigos e novos proprietários fundiários, os mecanismos de açambarcamento ou roubo e concentração de terras adquirem formas inusitadas, com alto teor de violência e repressão contra as comunidades indígenas e o campesinato pobre. Formas violentas de expropriação das terras e territórios comunais indígenas na região leste do país, seguidas de expulsão e extermínio tanto das populações nativas quanto de suas lideranças;

20 Grandes propriedades de terras também foram adquiridas pelo capital do narcotráfico, ou mais exatamente pelas máfias do narcotráfico, cujos integrantes, ao longo das décadas de 1970-1980, eram indivíduos pertencentes de algumas famílias latifundiárias e que alguns deles faziam parte do exército, como o caso da família do ditador Banzer, que utilizava as embaixadas e consulados bolivianos no exterior, principalmente nos Estados Unidos, como balcão de negócios do narcotráfico no período da ditadura militar com conhecimento dos governos estadunidense da época. O primo de Banzer, Roberto Suárez Gomez, foi um dos maiores chefes do cartel boliviano da cocaína na década de 1980, possuindo extensas propriedades fundiárias no departamento de Beni. Todavia, boa parte da oficialidade (meio e alto escalão) do exército boliviano estava envolvido com o narcotráfico: além da família Banzer, o general García Meza, o coronel L. A. Gomez, entre outros, perpetraram um golpe de Estado em 1980 financiado pela máfia do narcotráfico, passando esses militares a açambarcar grandes propriedades de terra na região leste do país. Na década 1980 se deflagraram grandes escândalos envolvendo militares, políticos e empresários envolvidos com o narcotráfico (os casos "Huanchaca" e "narcoavião"). Cf. LAB-IEPALA (1982), Rodas (1996) e Duran (2000).

$21 \quad$ Lei de Reforma Agrária de 1996, sob o primeiro governo Sánchez de Lozada. 
anexação aberta e arbitrária de terras fiscais e comunais por parte de setores da burguesia cruceña especialmente de grandes parques florestais na região leste. ${ }^{22}$

Do lado da massa camponesa e indígena igualmente se detectam mecanismos defensivos inusitados de luta pela terra: luta não somente pela terra (reforma agrária), mas também pelos territórios tradicionais indígenas. Surge, assim, a luta pela autonomia indígena e pela diversidade das nações indígenas com caráter pluriétnico e plurinacional, ao mesmo tempo que se integra à luta pela terra e território: as terras comunais devem ser autonomamente administradas (região e municípios) pelos próprios indígenas. Essa reivindicação ocorre ao longo da década de 1990 e se consolida no final da mesma com a unificação da luta entre os indígenas das terras altas e baixas (regiões andina, sub-andina e tropical). O partido MAS capitalizará essas reivindicações e as incluirá na sua plataforma política: luta pela terra e território e pela autonomia indígena com caráter plurinacional.

\section{CONCLUSÃO}

Ao longo deste trabalho temos analisado aos traços essenciais da política agrária boliviana e a estrutura da terra correspondente desde 1953, passando revista, grosso modo e esquematicamente, pelos regimes populistas (governos do MNR: 1952-64), militar (1964-82), neoliberal (1985-2005) que vigorará até chegar ao governo Morales. Pelo menos a década de 2000. Detectamos que, ao longo de 50 e 60 anos, a política agrária estatal não modificou substancialmente a estrutura agrária definida logo após a Revolução Nacional de 1952, iniciada na Reforma Agrária de 1953, cuja tentativa foi a de desenvolver a capitalização do campo e a realização de planos de desenvolvimento capitalista para auxiliar a indústria com o fim de abandonar a importação de grãos e alimentos - um tipo de substituição de importações num país dependente e periférico. A política agrária de longo prazo contribuiu com a reprodução da estrutura agrária do país iniciada na década de 1950. A análise de tal política e da estrutura agrária revelou suas contradições, ambiguidades, retrocessos e conflitos entre as classes proprietárias e as grandes massas trabalhadoras, camponesas e indígenas. Basicamente revelou um padrão ou tipo de reforma agrária peculiar: a política agrária boliviana adotou um

22 O caso mais emblemático nos últimos anos é o do conspícuo latifundiário e representante da burguesia agroindustrial, o caudilho Marinkovic, integrante do Comitê Cívico de Santa Cruz. Além de comprar votos para conquistar a direção do comitê, principal bastião da oposição autonomista contra o governo Morales, incita abertamente a violência no campo, semeando terror nas comunidades indígenas e se apropriando de suas terras (apropriação da Laguna Corazón no território indígena guarayo no leste do país). Em 2007 e 2008, o poder público, acionado pelo Instituto Nacional de Reforma Agrária (INRA) e o ministério do ramo, entrou com processo jurídico contra esse dirigente cívico pela apropriação ilegal de extensas terras fiscais e comunais indígenas (Cf. ECONOTICIAS BOLIVIA, 2008). 
padrão estrutural de Reforma Agrária conhecido como modelo junker, reproduzindo a longo prazo o grande latifúndio e o minifúndio, um processo de transformação capitalista do campo conduzida "pelo alto", caracterizada por nós como a dialética do latifúndio e do minifúndio. Tal processo de transformação capitalista revela, no caso boliviano, que é lento e eivado de lutas e conflitos sociais e que se alastra até a década de 2000.

\section{BIBLIOGRAFIA}

ALBÓ, Javier. Bodas de plata o requiem para una Reforma Agrária. Revista Paraguaya de Sociologia, no 35, p. 25-57, 1976.

ALBÓ, Xavier \& BARNADAS, Josep. La cara campesina de nuestra história. $\quad$ La Paz: Editora Universo, 1985.

ALEXANDER, Robert J. The Bolivian National Revolution. New Jersey: New Brunswick, 1958.

Bolivia: past, present, and future of its politics. New York: Praeger Publishers, 1982.

ANTEZANA Ergueta, Luis. Proceso y sentencia a la Reforma Agrária en Bolivia. La Paz: Puerta del Sol, 1979.

Bolivia: De la Reforma a la Contra Reforma Agrária. La Paz: Juventud, 1992.

ARRIETA, Mario; ÁBREGO, Guadalupe; DE LA FUENTE, Manuel. Agricultura en Santa Cruz: de la encomienda colonial a la empresa modernizada (1559-1985). La Paz: ILDIS, 1990.

BLASIER, Cole. The United States and the revolution. In: MALLOY, J.James. M.\&. \& THORN, RRichard. S. (Ed.). Beyond the revolution: Bolivia since 1952. Pittsburgh: University of Pittsburgh Press, 1971.

BOJANIC, Alan. Tenencia y uso de la tierra en Santa Cruz. Evaluación de la estructura agraria en el área integrada de Santa Cruz. La Paz: CEDLA, 1988.

CALDERON, Fernando; LASERNA, Roberto (comp.). El poder de las regiones. Cochabamba: CERES, 1983.

CARDOSO, Ciro. "Sobre los modos de producción coloniales de América Latina". In: C. S. Assadourian, et al, Modos de Producción en América Latina. $2^{\mathrm{a}}$ ed. Córdoba: Ediciones Pasado y Presente, 1974.

Escravo ou Camponês? O Protocampesinato Nero nas Américas.

São Paulo: Brasiliense, 1987. 
CARDOSO, Ciro F. S.; BRIGNOLI, Héctor P. História Econômica da América Latina. Rio de Janeiro: Graal, 1983.

CASANOVAS, W. Moore. Capital Acumulation and Revolutionary Nationalism in Bolivia, 1952-85”. In: ANGLADE, Christian; FORTIN, Carlos. The State and Capital Accumulation in Latin America. London: The Macmillan Press, 1990.

CASTILlO, Carpio; BALlERSTAEDT, Esther. Santa Cruz. La Reforma Agrária. La Paz: Grupo de Estudios Andrés Ibañez-CEUB, 1983. COMISIÓN ECONÓMICA PARA AMÉRICA LATINA - CEPAL. Campesinado y Desarrollo Agrícola en Bolivia. Santiago de Chile, 1982.

DANDLER, Jorge. El desarrollo de la agricultura, políticas estatales y el proceso de acumulación en Bolivia. Estudios Rurales Latino-Americanos, Vol. 7, nº 2, pp. 81-149, 1984.

DURAN Gil, Aldo. O narcotráfico nos governos militares e democráticos na Bolívia. Campinas: Premissas, ${ }^{\circ}$ 21, p. 55-72, 2000.

Estado Militar e Instabilidade Política na Bolívia (1971-1978). Tese de doutorado em Ciências Sociais, Instituto de Filosofia e Ciências Humanas, UNICAMP, 2003. Disponível em: 〈http://www.bibliotecadigital.unicamp.br/document/?code=vtls000311497>.

Bolívia e Equador no contexto atual. In: AYERBE, Luis Fernando (Org.). Novas lideranças políticas e alternativas de governo na América do Sul. São Paulo: UNESP e Programa San Tiago Dantas de Pós-Graduação em Relações Internacionais Unesp/Unicamp/ PUC-SP, 2008.

Bolívia: duas revoluções nacionalistas? Perspectivas Revista de Ciências Sociais, v. 33 pp. 157-188, 2008.

Aldo. A política agrária boliviana sob o governo Morales, São Paulo: Revista História \& Luta de Classes, v. 16, pp. 49-54, 2013.

ECKSTEIN, Susan \& HAGOPIAN, Frances. The Limits of Industrialization in the Less Developed World: Bolivia. University of Chicago Press: Economic Deveplopments na Developments and Cultural Change University of Chicago Press, vol. 33, $\mathrm{N}^{\mathrm{o}}$ 1, pp. 63-95, 1983.

ECKSTEIN, Susan. El capitalismo mundial y la revolución agrária en Bolivia. Revista Mexicana de Sociologia, v. 41, nº 2, p. 457-478, 1979.

ECONOTICIAS BOLIVIA. Branco, el fascista quiere derrocar a Evo. Disponível em: <http://www.econoticiasbolivia.com>. Acesso em 14 mar. 2008.

HEALY, Kevin. Caciques y patrones. Una experiencia de desarrollo rural en el sud de Bolivia. $3^{\text {a }}$ ed. Cochabamba: CERES, 1987.

HEALY, Kevin. Sindicatos Campesinos y Desarrollo Rural (1978-1985). La Paz: Hisbol, 1989. 
HUIZER, Gerrit \& STAVENHAGEN, Rodolfo. Movimientos campesinos y reforma agrária en América Latina: México e Bolívia. In: LANDSBERGER, HHenry. A. (ed.). Rebelión Campesina y Cambio Social. Barcelona: Editorial Crítica, 1978.

HUNTINGTON, Samuel. A Ordem Política nas Sociedades em Mudança. Rio de Janeiro: Forense Universitária, 1975.

INSTITUTO NACIONAL DE ESTADÍSTICA - BOLIVIA (INE). http://www.ine.gov.bo/asp/indicadores.asp?TI=2>. Bolivia en Cifras. Anuario 1973.

INSTITUTO NACIONAL DE ESTADÍSTICA - BOLIVIA (INE). Bolivia en Cifras 1980.

INSTITUTO NACIONAL DE ESTADÍSTICA - BOLIVIA (INE). Disponível em: <http://www.ine.gob.bo/default.aspx $>$. Acesso em: 20 oct. 2013.

LAB-IEPALA. Narcotráfico y Política. Militarismo y Máfia en Bolivia. Madrid: Iepala, 1982.

LAVAUD, Jean Pierre. L'instabilite Politique de l'Amérique Latine. Le cas bolivien. Paris: Editions l'Harmattan, 1991.

LENIN, Vladimir I. El Desarrollo del capitalismo en Rusia. Moscú: Editorial Progreso, 1981.

LORA, Guillermo. Tesis de Pulacayo (Tesis Central de la Federación de Trabajadores Mineros de Bolivia”.). In: LORA, Guillermo Lora. Documentos Políticos de Bolivia. La Paz: Futuro, .2 $2^{\mathrm{a}}$. ed. vol. II, 1987.

LORA, Guillermo. La Revolución Boliviana. La Paz : Ediciones Masas, 1996.

Inviabilidad de la Democracia. Proletariado y Nación Oprimida. La Paz: Ediciones El Amauta, 1980.

Ediciones Masas, 1983.

Causas de la Inestabilidad Política y de la Crisis de las FF.AA. La Paz: . La clase obrera después de 1952. México: Siglo XXI, 1987.

Bolivia: de la Asamblea Popular al Golpe Fascista". In: Estudios HistóricoPolíticos Sobre Bolivia. La Paz: El Amauta, 1978.

MALLOY, James. Bolivia: la Revolución Inconclusa. Cochabamba: CERES, 1989.

MALlOY, James; CONAGHAN, Catherine. Unsettling Statecraft. Democracy and Neoliberalism in the Central Andes. Pittsburgh: University of Pittsburgh Press, 1994.

MARTINS, José de Souza. O Cativeiro da Terra. São Paulo: Contexto, 2010.

MITCHEL, Christopher. Legacy of Populism in Bolivia: From the MNR to Military Rule. New York: Praeger, 1977. 
PIVA, Juliana Dal. Em luta pela terra sem mal. A saga guarani contra a escravidão na Bolívia. Rio de Janeiro: Multifoco, 2012.

POULANTZAS, Nicos. Pouvoir politic et classes sociales. Paris: Maspero, v.2, 1968.

1975. As classes sociais no capitalismo de hoje. Rio de Janeiro: Zahar Editores,

ROCA, J. Luis. Fisionomía del regionalismo boliviano. La Paz: Plural Editores, $2^{a}$ ed, 1999. RODAS, Hugo. Huanchaca. Modelo Político Empresarial de la Cocaína en Bolivia. La Paz: Plural Editores, 1996.

PRADO JÚNIOR, Caio. História econômica do Brasil. 19ª ed. São Paulo: Brasiliense, 1976.

REINAGA, Fausto. La revolución india. La Paz: PIEB, 1970.

RIVERA, Silvia. S. "Luchas Campesinas Contemporáneas en Bolivia: el Movimiento 'Katarista': 1970-1980. In: ZAVALETA, René Zavaleta (coord.). Bolivia Hoy. México: Siglo XXI, 1983.

RIVERA, Silvia. Oprimidos pero nos vencidos. Luchas del campesinado Aymara y Quechua, 1900-1980. La Paz: HISBOL-CSUTCB, 1984. . Violencias (re)encubiertas en Bolivia. Santander: Otramérica, 2012.

RIVERA, Silvia \& SANTOS, Boaventura Sousa. Conversa del Mundo - Silvia Rivera Cusicanqui y Boaventura de Sousa Santos. Vídeo publicado em 12 mar.2014. Disponível em: <https://www.youtube.com/watch?v=xjgHfSrLnpU>. Acesso em: 13 de jun. 2015.

ROCA, J. Luis. Fisionomía del regionalismo boliviano. $2^{\text {a }}$ ed. La Paz: Plural Editores, 1999.

RODAS, Hugo. Huanchaca. Modelo Político Empresarial de la Cocaína en Bolivia. La Paz: Plural Editores, 1996. La revolución india. La Paz: PIEB, 1970.

. Classe Média e Sistema Político no Brasil. São Paulo: T. A. Queiroz, 1985 (a).

. A formação do Estado burguês no Brasil (1888-1891). $2^{\mathrm{a}}$ ed. Rio de Janeiro, Paz e Terra, 1985 (b).

. Marxismo e história. São Paulo: Crítica Marxista, nº 1, p. 39-59, 1994.

. Coronelismo e Estado burguês: elementos para uma reinterpretação. In: Estado e democracia: ensaios teóricos. $2^{\text {a }}$ Ed. Campinas: UNICAMP/IFCH, 1998.

. República do Capital. São Paulo: Boitempo, 2001 (a).

. A questão da evolução da cidadania política no Brasil. Estudos Avançados: São Paulo, $\mathrm{n}^{\mathrm{o}}$ 42, v. 13 p. 379-410, 2001. Disponível em: <http://www.revistas.usp.br/eav/article/view/9813 $>$. Acesso em 23 mai. 2017. 
SAES, Décio. Modelos políticos latino-americanos na nova fase da dependência. In: NOGUEIRA, F. M. G. \&Francis Mary Guimarães; RIZZOTTO, M. L. F.Maria Lucia Frizon (org.). Políticas Sociais e Desenvolvimento: América Latina e Brasil. São Paulo, Xamã, p. 155-172, 2007.

SAES, Décio. As frações da classe dominante no capitalismo: uma reflexão teórica. Mimeo, 2014 (a).

Capitalismo e processo político no Brasil: a via brasileira para o desenvolvimento do capitalismo. Mimeo, 2014 (b).

THEOBALD, Robin. On the Survival of Patronage in Development Societies. Archives Européennes de Sociologie, Cambridge, nº 1, v. 33, p. 183-191, 1992.

YBARNEGARAY de Paz, Roxana. El espíritu del capitalismo y la agricultura cruceña. La Paz: CERID, 1992.

ZAVALETA, René. Lo nacional-popular en Bolivia. México: Siglo XXI, 1986. Nueva Sociedad, Caracas, n. 47, 1980.

Lo nacional-popular en Bolivia. México: Siglo XXI, 198 El Poder Dual. Problemas de la teoria del Estado en América Latina. La Paz: Los Amigos del Libro, $3^{\mathrm{a}}$ ed., 1987.

. 50 Años de Historia. La Paz: Los Amigos del Libro, 1992.

ZIBECHI, Raúl. El estado de excepción como paradigma político del extractivismo. In: COMPOSTO, Claudia; NAVARRO, Mina Lorena (Comp.). Territorios en disputa.

México: Bajo Tierra Ediciones, 2014. Disponível em $<$ http://otrosmundoschiapas.org/docs/territorios_en_disputa_bienes_comunes.pdf $>$. Acesso em: 25 set. 2016.

El extractivismo contra los pueblos de América Latina. Laboratorio de Paz, 18 ago. 2016. Disponível em: <http://laboratoriosdepaz.org/raul-zibechi-el-extractivismo-contralos-pueblos-de-america-latina/>. Acesso em: 25 set. 2016.

Recebido em 30/06/2017.

Aceito em 20/07/2017.

Publicado em 21/09/2017.

DOI: 10.11606/issn.1676-6288.prolam.2016.110116 